\title{
DIABETIC FOOT INFECTION; FREQUENCY OF MICROBES AND ANTIMICROBIAL SENSITIVITY PATTERN AT TERTIARY CARE HOSPITAL, KARACHI
}

\footnotetext{
1. FCPS (Medicine) consultant physician

Department of medicine ofLiaquat University hospital Hyderabad

2. FCPS (Medicine)

Assistant professor

Department of medicine Dow

Universityand Civil hospital Karach

3. MBBS, MPhil pathology

Associate Professor

National institute of

Cardiovascular disease Karachi
}

Correspondence Address:

Dr. Abdul Ghani Rahimoon

FCPS (Medicine), consultant physician

Department of medicine of Liaquat University hospital Hyderabad

saedarain@yahoo.com

Article received on: 19/06/2015

Accepted for publication:

27/07/2015

Received after proof reading:

$13 / 11 / 2015$

\section{Dr. Abdul Ghani Rahimoon', Muhammad Tanveer Alam², Muhammad Saeed Talpur ${ }^{3}$}

ABSTRACT... Objectives: To determine the frequency of common bacterial isolates cultured from diabetic foot infection in patients with type 2 diabetes mellitus (DM) falling in Wagner's grade-2 and grade-3 classification of diabetic foot (DF) infection. Study Design: Descriptive study. Period: A six months. Setting: Dow University of health sciences and civil hospital Karachi. Methods: Completed to examine the bacterial identification in cases admitted with the infection diabetic foot along with gave Wagner's evaluation 2 and 3 at tertiary care hospital Karachi. Bacteriological finding and anti-biotic affectability profiles were completed and analyzed with utilizing standard strategies. Results: Out of 115 cases, $82(71 \%)$ were male and $23(29 \%)$ were female. The mean age of patients was $51.7 \pm 9.45$ years, mean duration of diabetes was 10.6 \pm 4.73 years, similarly mean length of time of diabetes foot wound was $46.15 \pm 23.75$ days. 45 (39\%) patients had Wegner's evaluation 2 and 70 (61\%) patients had Wagner's evaluation 3. 99 cases indicated with culture growth, out of which $65(65.65 \%)$ with gram negative microbes and 25 (25.25\%) gram-positive microbes. The most successive bacteria's were Proteus (35.35\%), Staph. Aureus (25.25\%), Klebsiella (16.16\%) and Pseudomonas (15.15\%). Both gram positive and gram negative showed frequent resistance to Cloxacillin, Amoxacillin, Levofloxacin, and Linezolid, gram negative life forms likewise indicated high resistance rate to Clindamycin, Vancomycin, and Cefotaxime. Tienam (Imipenem), Sulzone (salbactam in addition to cefoperazone) and Amikacin were the best effective against gram -ve and gram +vemicrobes. Staph. Aureus and Staph. Epidermidis were profoundly susceptible to Ciprofloxacin, Ceftriaxone, Clindamycin, and Vancomycin. Conclusion: Gram negative microbes were more common than gram positive living beings. Proteus, Staph Aureus, Klebsiella and Pseudomonas aeruginosa were the most widely recognized microorganisms of DF infection. Tienam (Imipenem), Sulzone (salbactam in addition to cefoperazone), and Amikacin were best effective agents.

Key words: $\quad$ Diabetes mellitus, Diabetic foot infection, Diabetic foot microbiology.

Article Citation: Rahimoon AG, Alam MT, Talpur MS. Diabetic foot infection; frequency of microbes and antimicrobial sensitivity pattern at tertiary care hospital, Karachi. Professional Med J 2015;22(11):1415-1422. DOI: 10.17957/TPMJ/15.2991

\section{INTRODUCTION}

Diabetes Mellitus is metabolic problem differentiated due to hyperglycemia because of deformities in insulin secretion, insulin activity or both. ${ }^{\mathrm{D} M}$ is the common endocrine issue and one of the biggest health issues. DM influences $5-10 \%$ of United Stated populations eventually in their lives. ${ }^{2}$ The assessed incidence of diabetes among adults is $7.4 \%$ in 1995, which is relied upon to ascend to $9 \%$ in 2025. ${ }^{3}$ In Pakistan different studies have mentioned incidence between $5-7 \%{ }^{4} \mathrm{DM}$ II is $7-8$ times more regular than DM type one, however this proportion shifts with age, being lower in younger's and higher in adult age. ${ }^{5}$ The diabetic case is vulnerable to a progression of complications which are increase the morbidity. Hyperglycemia creates grave complications and disappointment of different organs like eyes, kidneys, nerves, heart and veins. Peripheral neuropathy is a standout amongst the most serious of these which prompts grower foot ulceration. ${ }^{2}$ DF ulcer or gangrene is a main reason for morbidity and mortality in people having DM. ${ }^{6}$ Diabetic foot illness is found in 40-60 years $98 \%$ with DM type 2. Nearly $10-25 \%$ of all diabetics create foot issues over throughout their disease from basic calluses to significant abscesses and osteomyelitis. ${ }^{7} 40-80 \%$ ulcers in the long run get to be contaminated. The reason behind expanded frequency of this issue in DM includes coopera- 
tion of a few pathogenic components i-e. Neuropathy, irregular foot biomechanics, blood vessel issue and poor injury healing.,9By different investigation, it was found that there are four statically critical danger components for foot disease i-e wounds that entered to bone, intermittent injuries, injuries of long span (30), and peripheral vascular disease. ${ }^{10} \mathrm{DF}$ issues are in charge of almost $50 \%$ of all diabetes related healing facility affirmations, such confirmation have a tendency to be delayed and may end with removal of foot. ${ }^{11,12}$ Many diabetic appendage removals could be deferred or prevent by more powerful understanding's instruction and restorative supervision. ${ }^{13}$

DF ulcer should care in everything every stage to control mechanical injury, microbiological, vascular, metabolic and instructive aspects. ${ }^{14}$ In DF contamination, microbiology has affectability and specificity of 92 and $60 \%$ respectively. ${ }^{15}$ DF contaminations are additionally separated into two classes non-limb threatening and limb threatening. Non-limb infections are superficial with insignificant cellulites $(<2 \mathrm{~cm})$, don't include bone or joint, lack ischemia and are normally brought on by Staphylococcus aureus. ${ }^{16}$ Limb threatening contaminations are more serious, have more prominent than two centimeters of cellulites, include more deep structure, for example, bones and joints and may have ischemia. The normal number of confines per contamination among patients hospitalized with pedal diseases is 3-4. ${ }^{17}$ Staphylococci and streptococci are the most widely recognized pathogens however contaminations because of gram negative bacilli and anaerobes happen in roughly $50 \%$ of cases. ${ }^{18} \mathrm{Com}-$ monly separated aerobic gram-negative bacilli incorporate proteus species, klebsiella species, Escherichia coli and pseudomonas species. ${ }^{19} \mathrm{In}$ contrast, severe infections are often polymicrobial, requiring hospitalization and treatment with broad spectrum antibacterial along with appropriate medical and surgical interventions. ${ }^{20}$ The need to conduct this study is to determine the frequency of common microorganisms in diabetic foot infection and their sensitivity pattern in local tertiary health care setup, which may subsequently help to plan out to start appropriate empirical antibiotic therapy.

\section{SUBJECTS AND METHODS}

Descriptive case series study conducted at Dow University of health sciences and civil hospital Karachi, with six months and contains 115 cases. All cases of either age or sex who were diagnosed with type 2 DM and had diabetic foot falling in Wagner's grading 2 and 3 were included. Cases with varicose veins of lower limb, bed ridden, paraplegic, taking antibiotic before presentation, and Wagner's grade $>3$ were excluded.

A proforma was used to collect data. Informed consent for the study was obtained from each selected patient. A detailed history was taken including age, sex, duration of diabetes (in years) and diabetic foot (in days). These patients were clinically assessed and the foot lesions were graded depending on the severity of lesions as Grade-2 or 3 (grade 2 is deep ulcer without bone enrolment or abscesses formation and grade 3 is deep ulcer with bone involvement or abscesses formation). Pus aspirates from the abscesses and derided necrotic materials were collected for aerobic and anaerobic culture. Examples were sent to microbiological research center where a Gram stains direct spread and was analyzed. The bacterial identification was distinguished by traditional biochemical tests. Antimicrobial helplessness testing was performed by Kirby Bauer's disc diffusion system as indicated by National Committee for Clinical Laboratory Standards (NCCLS) rules. The patients were treated with antibacterial treatment as indicated by culture and antibacterial susceptibility pattern.

\section{RESULTS}

A total of 115 diagnosed cases of type 2 DM and having DF infection with Wagner's grade 2 and 3 were included in this study. Out of 115 cases, $82(71 \%)$ were male and $23(29 \%)$ were female cases, male to female ratio being 3.56:1.

Eighty three (72.1\%) cases were 41 to 60 years of age, as presented in figure 1 . Mean age of cases was $51.7 \pm 9.45$ years $(95 \% \mathrm{Cl}: 49.95$ to 53.44$)$. Duration of diabetes was $10.6 \pm 4.73$ years 
(95\%Cl: 9.73 to 11.47 ) and $32.26 \%$ cases had the condition for $>10$ years. Similarly Duration of DF wound was $46.15 \pm 23.75$ days $(95 \% \mathrm{Cl}$ : 41.76 to 50.54) days. Table-I.

According to Wagner's classification, 45(39\%) cases had grade 2 and $70(61 \%)$ cases had grade 3 DF wound. Figure-1.

Frequency of microbes in DF infection in cases with type $2 \mathrm{DM}$ is presented in Table-II. Microbes were found in $99(86.1 \%)$ cases, total number of organisms was 108 , and ratio of organisms per case was 1.09. Gram-positive aerobic organisms were found in 25 cases (25.25\%) and 71 cases $(71.71 \%)$ had gram-negative aerobes. Out of 99 positive cultures, 85 (85.85\%) specimen showed single organism (monomicrobial) and 14 (14.15\%) had mixed infection (polymicrobial).

Proteus was the most common isolate, accounting for $35.35 \%$; followed by Staphylococcus aureus $25.25 \%$, Klebsiella $16.16 \%$, pseudomonas $15.15 \%$, Enterococci and Enterobactor comprising 4.04\% each, E Coli 3.03\%, Staph. Epidermidis $2.02 \%$, Moraganella and Salmonella Typhi were observed in $2.02 \%$ each as shown in Table-II. Similarly common microorganisms in DF infection in cases with respect to gender, are presented in Table-III.

The results of the test for susceptibility to the commonly used antibiotics are shown in table.11 Staph. Aureus showed resistance to Linezolid (100\%), Levofloxacin (92\%), Amoxicillin (72\%) and Cloxacillin (72\%) and was sensitive to Ciprofloxacin (88\%), Ceftriaxone (92\%), Amikacin (96\%), Clindamycin (64\%), Vancomycin (88\%), Tienam (100\%) and Sulzone (100\%). S. Epidermidisshowed absolute resistance toCloxacillin, Cefotaxime, Linezolid, Amoxicillin and absolute sensitivity to Ciprofloxacin, Ceftriaxone, Amikacin, Clindamycin, Vancomycin, and Tienam. E. coliwere absolute resistant to Cloxacillin, Clindamycin, Levofloxacin, Linezolid, Amoxicillin, and Vancomycin while sensitivity was shown to Ciprofloxacin, Ceftriaxone, Cefotaxime and Amikacin $(67 \%)$ in each. And absolute sensitivity with Tie- nam (100\%) and Sulzone (100\%).

Proteus showed resistant to Cloxacillin (91\%), Clindamycin (89\%), Levofloxacin (74\%), Cefotaxime (63\%), Linezolid (74\%) and Amoxicillin (94\%), while Proteus was sensitive to Ciprofloxacin (51\%), Amikacin (66\%), Tienam (97\%), and Sulzone (100\%) Enterococci was absolute resistant to all commonly used antibiotics except only sensitive to Ceftriaxone (75\%), Amikacin, Tienam and Sulzone (100\%) in each

Pseudomonas, Moraganella, Enterobactor, Klebsiella and Salmonella Typhi were absolute sensitive to Tienam and Sulzone and very high resistance $(75-100 \%)$ was shown to Cloxacillin, Clindamycin, Levofloxacin, Cefotaxime, Linezolid, Amoxicillin, and Vancomycin. Pseudomonas was also sensitive to Ciprofloxacin (80\%) and Amikacin (80\%). Moraganella showed absolute sensitivity to Ciprofloxacin, Ceftriaxone, and Amikacin. Enterobactor, Klebsiella, and Salmonella Typhi was also sensitive to Amikacin (100\%).

\begin{tabular}{|l|c|}
\hline \multicolumn{1}{|c|}{ Characteristics } & Mean \pm SD \\
\hline AGE (Years) & $51.7 \pm 9.45$ \\
\hline FBS (mg/dl) & $133.77 \pm 35.67$ \\
\hline $\begin{array}{l}\text { Duration of DM Type 2 (Years) } \\
\text { Duration of DF wound (days) }\end{array}$ & $10.60 \pm 4.73$ \\
\hline $\begin{array}{l}\text { GENDER } \\
\text { male } \\
\text { female }\end{array}$ & $46.15 \pm 23.75$ \\
\hline \multicolumn{2}{|c|}{ Table-I Basic Characteristics Of Study Variables } \\
\\
\multicolumn{2}{|c|}{$\mathrm{n}=115$}
\end{tabular}

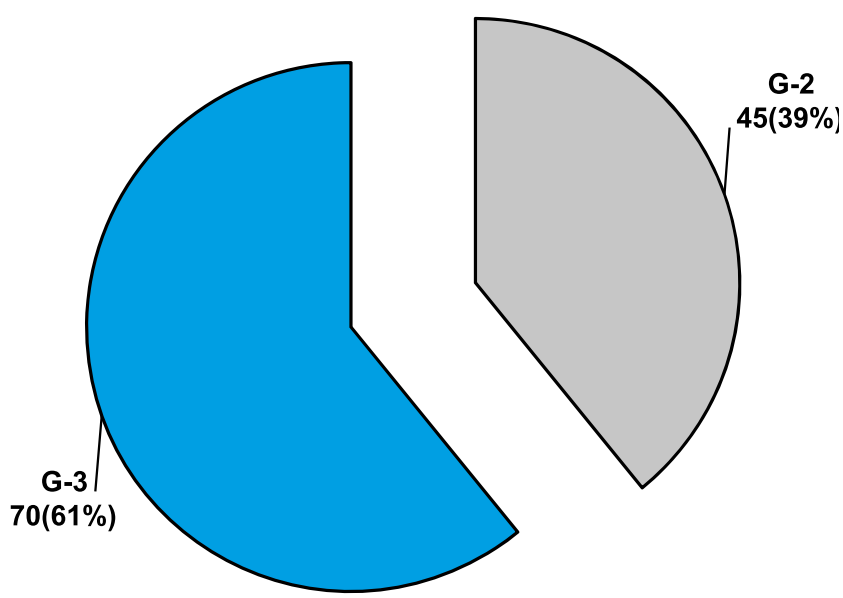

Figure-1. Wagner's Grading Of Diabetic Foot n=115 


\begin{tabular}{|l|c|c|}
\hline Common Microorganisms & Count & Percentage \\
\hline Proteus & 35 & $35.35 \%$ \\
\hline Staphylococcus. Aureus & 25 & $25.25 \%$ \\
\hline Klebsiella & 16 & $16.16 \%$ \\
\hline Pseudomonas & 15 & $15.15 \%$ \\
\hline Enterococci & 4 & $4.04 \%$ \\
\hline Enterobactor & 4 & $4.04 \%$ \\
\hline E. Coli & 3 & $3.03 \%$ \\
\hline Staph. Epidermidis & 2 & $2.02 \%$ \\
\hline Moraganella & 2 & $2.02 \%$ \\
\hline Salmonella Typhi & 2 & $2.02 \%$ \\
\hline Table-II. Common Causative Organisms for Bacterial \\
\multicolumn{2}{|c|}{ Infection in DF Infection in Cases With } \\
\multicolumn{2}{|c|}{ Type 2 Diabetes Mellitus n=99 } \\
\hline
\end{tabular}

\begin{tabular}{|l|c|c|c|}
\hline \multicolumn{1}{|c|}{ Microorganisms } & Male & Female & Total \\
\hline Proteus & 29 & 6 & 35 \\
\hline Staph. Aureus & 20 & 5 & 25 \\
\hline Klebsiella & 11 & 5 & 16 \\
\hline Pseudomonas & 15 & 0 & 15 \\
\hline Enterococci & 4 & 0 & 4 \\
\hline Enterobactor & 2 & 2 & 4 \\
\hline E Coli & 1 & 2 & 3 \\
\hline Staph. Epidermidis & 2 & 0 & 2 \\
\hline Moraganella & 2 & 0 & 2 \\
\hline Salmonella Typhi & 2 & 0 & 2 \\
\hline Table-III. Common Microorganisms in DF Infection in \\
\multicolumn{2}{|c|}{ Cases With Respect to Gender $\mathrm{n}=99$} \\
\hline
\end{tabular}

\begin{tabular}{|c|c|c|c|c|c|c|c|c|c|c|c|}
\hline \multirow[t]{2}{*}{ Antibiotics } & \multicolumn{2}{|c|}{$\begin{array}{l}\text { S. Aureus } \\
n=25\end{array}$} & \multicolumn{2}{|c|}{$\begin{array}{c}\text { S. } \\
\text { Epidermidis } \\
\mathrm{N}=2\end{array}$} & \multicolumn{2}{|l|}{$\begin{array}{c}\text { E Coli } \\
n=3\end{array}$} & \multicolumn{3}{|c|}{$\begin{array}{c}\text { Enterococci } \\
\qquad N=4\end{array}$} & \multicolumn{2}{|c|}{$\begin{array}{c}\text { Proteus } \\
n=35\end{array}$} \\
\hline & $S$ & $\mathrm{R}$ & $S$ & $\mathrm{R}$ & $S$ & $\mathrm{R}$ & $S$ & \multicolumn{2}{|r|}{$\mathrm{R}$} & \multicolumn{2}{|c|}{$R$} \\
\hline Ciprofloxacin & $88 \%$ & $12 \%$ & $100 \%$ & $0 \%$ & $67 \%$ & $33 \%$ & $50 \%$ & \multicolumn{2}{|r|}{$50 \%$} & $51 \%$ & $49 \%$ \\
\hline Ceftriaxone & $92 \%$ & $8 \%$ & $100 \%$ & $0 \%$ & $67 \%$ & $33 \%$ & $75 \%$ & \multicolumn{2}{|r|}{$25 \%$} & $49 \%$ & $51 \%$ \\
\hline Amikacin & $96 \%$ & $4 \%$ & $100 \%$ & $0 \%$ & $67 \%$ & $33 \%$ & $100 \%$ & \multicolumn{2}{|r|}{$0 \%$} & $66 \%$ & $34 \%$ \\
\hline Cloxacillin & $28 \%$ & $72 \%$ & $0 \%$ & $100 \%$ & $0 \%$ & $100 \%$ & $0 \%$ & \multicolumn{2}{|c|}{$100 \%$} & $9 \%$ & $91 \%$ \\
\hline Clindamycin & $64 \%$ & $36 \%$ & $100 \%$ & $0 \%$ & $0 \%$ & $100 \%$ & $0 \%$ & \multicolumn{2}{|c|}{$100 \%$} & $11 \%$ & $89 \%$ \\
\hline Levofloxacin & $8 \%$ & $92 \%$ & $50 \%$ & $50 \%$ & $0 \%$ & $100 \%$ & $0 \%$ & \multicolumn{2}{|c|}{$100 \%$} & $26 \%$ & $74 \%$ \\
\hline Cefotaxime & $48 \%$ & $52 \%$ & $0 \%$ & $100 \%$ & $67 \%$ & $33 \%$ & $50 \%$ & \multicolumn{2}{|r|}{$50 \%$} & $37 \%$ & $63 \%$ \\
\hline Linezolid & $0 \%$ & $100 \%$ & $0 \%$ & $100 \%$ & $0 \%$ & $100 \%$ & $0 \%$ & & $100 \%$ & $23 \%$ & $74 \%$ \\
\hline Amoxicillin & $28 \%$ & $72 \%$ & $0 \%$ & $100 \%$ & $0 \%$ & $100 \%$ & $0 \%$ & & $100 \%$ & $6 \%$ & $94 \%$ \\
\hline Vancomycin & $88 \%$ & $12 \%$ & $100 \%$ & $0 \%$ & $0 \%$ & $100 \%$ & $0 \%$ & & $100 \%$ & $6 \%$ & $94 \%$ \\
\hline Tienam & $100 \%$ & $0 \%$ & $100 \%$ & $0 \%$ & $100 \%$ & $0 \%$ & $100 \%$ & & $0 \%$ & $97 \%$ & $3 \%$ \\
\hline Sulzone & $100 \%$ & $0 \%$ & $50 \%$ & $50 \%$ & $100 \%$ & $0 \%$ & $100 \%$ & & $0 \%$ & $100 \%$ & $0 \%$ \\
\hline Antibiotics & $\begin{array}{r}\text { Pseud } \\
n=\end{array}$ & $\begin{array}{l}\text { monas } \\
15\end{array}$ & $\begin{array}{r}\text { Moras } \\
\mathbf{N}\end{array}$ & $\begin{array}{l}\text { anella } \\
=2\end{array}$ & $\begin{array}{l}\text { Enterobactor } \\
\qquad n=4\end{array}$ & & $\begin{array}{l}\text { Kleb } \\
\mathrm{n}=\end{array}$ & $\begin{array}{l}\text { siella } \\
=16\end{array}$ & & $\begin{array}{r}\text { Salmon } \\
n\end{array}$ & a Typhi \\
\hline & $S$ & $\mathrm{R}$ & $S$ & $\mathrm{R}$ & $S$ & $\mathrm{R}$ & & $S$ & $\mathrm{R}$ & $S$ & $\mathrm{R}$ \\
\hline Ciprofloxacin & $80 \%$ & $20 \%$ & $100 \%$ & $0 \%$ & $50 \%$ & $50 \%$ & & $63 \%$ & $38 \%$ & $0 \%$ & $100 \%$ \\
\hline Ceftriaxone & $33 \%$ & $60 \%$ & $100 \%$ & $0 \%$ & $25 \%$ & $75 \%$ & & $88 \%$ & $13 \%$ & $0 \%$ & $100 \%$ \\
\hline Amikacin & $80 \%$ & $20 \%$ & $100 \%$ & $0 \%$ & $100 \%$ & $0 \%$ & & $100 \%$ & $0 \%$ & $100 \%$ & $0 \%$ \\
\hline Cloxacillin & $0 \%$ & $100 \%$ & $0 \%$ & $100 \%$ & $0 \%$ & $100^{\circ}$ & & $6 \%$ & $88 \%$ & $0 \%$ & $100 \%$ \\
\hline Clindamycin & $7 \%$ & $93 \%$ & $0 \%$ & $100 \%$ & $0 \%$ & $100^{\circ}$ & & $13 \%$ & $88 \%$ & $0 \%$ & $100 \%$ \\
\hline Levofloxacin & $0 \%$ & $87 \%$ & $0 \%$ & $100 \%$ & $25 \%$ & $75 \%$ & & $0 \%$ & $100 \%$ & $0 \%$ & $100 \%$ \\
\hline Cefotaxime & $7 \%$ & $93 \%$ & $0 \%$ & $100 \%$ & $25 \%$ & $75 \%$ & & $63 \%$ & $38 \%$ & $0 \%$ & $100 \%$ \\
\hline Linezolid & $0 \%$ & $100 \%$ & $0 \%$ & $100 \%$ & $0 \%$ & $100^{\circ}$ & & $0 \%$ & $100 \%$ & $0 \%$ & $100 \%$ \\
\hline Amoxicillin & $0 \%$ & $100 \%$ & $0 \%$ & $100 \%$ & $0 \%$ & $100^{\circ}$ & & $13 \%$ & $88 \%$ & $0 \%$ & $100 \%$ \\
\hline Vancomycin & $0 \%$ & $100 \%$ & $0 \%$ & $100 \%$ & $25 \%$ & $75 \%$ & & $31 \%$ & $69 \%$ & $0 \%$ & $100 \%$ \\
\hline Tienam & $100 \%$ & $0 \%$ & $100 \%$ & $0 \%$ & $100 \%$ & $0 \%$ & & $100 \%$ & $0 \%$ & $100 \%$ & $0 \%$ \\
\hline Sulzone & $100 \%$ & $0 \%$ & $100 \%$ & $0 \%$ & $100 \%$ & $0 \%$ & & $94 \%$ & $6 \%$ & $50 \%$ & $50 \%$ \\
\hline
\end{tabular}




\section{DISCUSSION}

Diabetes is a typical illness influencing around $2 \%$ of the world's population; it influences around $10 \%$ of our population. About $10-25 \%$ of all diabetics add to some foot issues over the duration of their disease from straightforward calluses to real abscesses and osteomyelitis. ${ }^{7}$ Foot ulcer is a critical difficulty of DM and regularly goesto lower limit amputation. Despite the fact that contamination is often involved in the etiology of DF ulcers, the ulcers are helpless to disease once the injury is available. Foot disease and the amputation of lower limbs are the most widely recognized reason for hospitalization among diabetic cases. ${ }^{21}$ It is more mostly seen in male and age of $40-60$ years. ${ }^{7}$

Mean age of cases was $51.7 \% \pm 9.45$ years; it is similar to previous studies which were done by Gadapali R et al, ${ }^{22}$ and also by Alavi SM et al. ${ }^{21}$ Out of 115 cases male were $82(71 \%)$, this same male to female ratio $(3.5: 1)$ presented by Jamil $M,{ }^{23}$ and also by Rooh- ul-Muqium.Error! Bookmark not

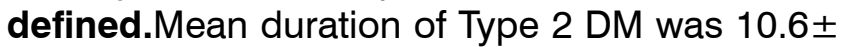
4.73 years and mean duration of DF wound was $46.15 \pm 23.75$ days, it was same in Gadapali. ${ }^{22}$

All the cases in this study were hospitalized due to the severity of their foot ulcers which categorized into grade 2 to 3 according to Wagner's classification. We could not find any significant differences between the variety of isolated organisms and the grade of ulcers but the load of the same organisms were higher in cases with grade 3 , which was also seen in previous studies by Rooh- ul-Muqium and others. ${ }^{7}$

Out of 115 specimen 99 (86.1\%) showed positive culture growth and 16 (13.9\%) had no growth, compared with previous study done by Alavi SM et al, ${ }^{21}$ showed no growth of bacterial culture in $18.8 \%$. Proteus (35.35\%), Staph. Aureus (25.25\%), Klebsiella (16.16\%), and Pseudomonas $(15.15 \%)$ were the commonest isolate, which was in agreement to studies of El-Tahaway, ${ }^{24}$ and Lipsky BA et al. ${ }^{25}$ But in contrast, studies done by Sharma VK et al, ${ }^{26}$ and almost similarly in Abdulrazak $A$ et al ${ }^{27}$ who showed that the most frequent organisms were Staph. Aureus (38.4\%), Proteus (17.4\%), and Pseudomonas (14\%). A study published in local journal was done by Alavi SM et al, ${ }^{21}$ showed that most frequent organisms were Staph. Aureus (26.19\%), E. coli (23.8\%), Staph. Epidermidis (14.3\%) and Proteus (11.9\%). Another study in local journal was done by Jamil $M$ et al, ${ }^{23}$ showed Staph. Aureus (50\%), Pseudomonas (25\%) and Streptococci (8\%). Difference in frequency of microorganisms could be because of major bulk of cases had grade-3 (deeper) DF ulcer, so in previous studies showed that $\mathrm{S}$. Aureus and streptococci frequently found in mild superficial DF infection and gram negative organisms i-e Proteus, Klebsiella, Pseudomonas, and E. Coli were frequently found in deeper foot infections. ${ }^{24}$

In this study gram negative aerobes were $71.71 \%$, out of which Proteus was most common organism. Gram positive aerobes were $25.25 \%$, Staph. Aureus was the most frequent organism. Gram negative anaerobes were $4.04 \%$, Enterobacter spp: was only micro-anaerobes found. Hence the ratio of gram negative to positive organisms (3:1) remained same as previously in Gadapali et al, ${ }^{22}$ and Ansari S et al. ${ }^{28}$

Out of 99 positive specimens fourteen (14.15\%) were polymicrobial and $85(85.85 \%)$ were monomicrobial. In contrast, study by Raja NS, ${ }^{29}$ in Malaysia at tertiary care hospital, showed polymicrobial infection in $43 \%$, while in other previous studies polymicrobial infections were $80-87 \%$ also. Difference in polymicrobial vs monomicrobial results from previous studies could be because of, we included only Wagner's grade 2 and grade 3 , comparatively less severe foot ulcer. A previous study showed that less severe DF ulcer infections were predominant monomicrobial infection. ${ }^{24}$

$60-70 \%$ isolated bacteria showed resistance to commonly prescribed antibiotics. This was a higher resistance rate compared to similar work of Hartmann et al, ${ }^{30}$ where they found $18 \%$ multidrug resistant. Proteus showed high resistance to Amoxycillin (94\%), Vancomycin (94\%), Cloxacillin (91\%), Clindamycin (89\%), Levofloxacin and Linezolid were $74 \%$ each, but highly sensitive to 
Sulzone (100\%), Tienam (97\%), and Amikacin (66\%). Staph. Aureus showed high resistance to Cloxacillin (72\%), Amoxycillin (72\%), Levofloxacin (92\%), and Linezolid (100\%), but highly sensitive to Tienam (100\%), Sulzone (100\%), Amikacin (96\%), Ceftriaxone (92\%), Vancomycin and Ciprofloxacin were $88 \%$ each. Staph. Epidermidis showed highly resistant all antibiotics except Tienam, Ciprofloxacin, Ceftriaxone, and Amikacin were sensitive $100 \%$ each. All other gram negative isolates i-e Klebsiella, Pseudomonas, E.coli, Morgnella, and Enterobacter showed highly sensitive to Tienam (Imipenem), Sulzone (salbactam + cefoperazone) and Amikacin. A similar study was done at microbiology department in govt. medical college Chandigarh, India by Basal E et al, ${ }^{31}$ where showed absolute sensitivity to Imipenem and Sulzone. All gram negative isolates were resistant to commonly prescribed antibiotics except Pseudomonas, E Coli, Klebsiella and Morgnella, these were sensitive to ciprofloxacin $80 \%$, $67 \%, 63 \%$ and $100 \%$ respectively. Klebsiella, E Coli, Enterococci and Morgnella also showed sensitivity to Ceftriaxone $88 \%, 67 \%, 75 \%$ and $100 \%$ respectively. Similar pattern of drug sensitivity was found in Sharma VK, ${ }^{26}$ Raja NS, ${ }^{29} \mathrm{Ab}$ dulrazak $\mathrm{A}$ et al, ${ }^{28}$ and El-Tahawy, ${ }^{24}$ who showed gram negative organisms were highly sensitive to Imipenem and gram positive organisms were sensitive to Vancomycin. A local study Alavi SM et al, ${ }^{21}$ showed high resistance rate to all commonly prescribed antibiotics except ciprofloxacin, Amikacin, and Ceftriaxone. In contrast a local study done by Ansari $S$ et al, ${ }^{28}$ who showed all isolates were uniformly susciptable to Levofloxacin, Amikacin and Vancomycin.

In this study the differences in sensitivity pattern of antibiotics could be because, Imipenem (Tienam) and Sulzone (Cefoperazone plus Salbactam) are novel broad spectrum antibiotics. Previously these were not commonly prescribed in public sector hospitals because of non-availability of drugs and cost problem, hence majority of cases were not exposed to these drugs, that is why these were most effective antibiotics in DF infection.

\section{CONCLUSION}

DF infection was more common in males than females and common age group was 40-60 years. Gram negative organisms were frequently found as compared to gram poitive organisms and predominately DF infections were monomicrobial in nature. Proteus vulgaris, Staphylococcus Aureus, Pseudomonas and Klebsiella were the most common organisms in DF infections. The rate of culture senstivity was $86 \%$ among all cases. The gram positive and gram negative organisms were highly resistant to Levofloxacin, Linezolid, Cloxacillin and Amoxicillin, gram negative also showed high rate of resistance to Clindamycin and Vancomycin. In antimicirobial sensitivity pattern, it was showed that both gram positive and gram negative organisms were highly susciptable to Tienam, Sulzone, and Amikacin. Gram positive organisms were also susciptable to Vancomycin, Ceftriaxone and ciprofloxacin.

Copyright (C) 27 July, 2015.

\section{REFRENCES}

1. Report of the Expert Committee on the diagnosis and classification of Diabetes mellitus. Diabetes Care. Jan 2001: 24; (Suppl.1) S5-12.

2. Weiman JJ. Principles of management; the diabetic foot. Am J Surg. Aug 2005;190:295-9.

3. American Diabetes Association. Screening for DM (Position Statement) Diabetes Care. Jan 2001; 24: (Suppl. 1); S21.

4. Shera AS, Diabetes mellitus. A major health problem in Pakistan. Diabetes Digest 1992:7-9.

5. Faucini. Harrison's Principles of Internal Medicine. Mc Graw-Hill ed. 1998:2;2060-80.

6. Unachukwu CN, Obunqe OK, Odia OJ. The bacteriology of DF ulcers in Port Harcourt, Nigeria. Niger J Med 2005;14:173-6.

7. Rooh-Ul-Muqim, Ahmed M, Griffin S. Evaluation \& management of DF infection according to Wagner's classification - a study of $\mathbf{1 0 0}$ cases. J Ayub Med Coll Abottabad 2003;15:39-42.

8. Powers AC. Diabetes mellitus. In: Kasper DL, Braunwald E, Fauci AS, Hauser SL, Longo DL, Jamsen JL. Harrison's principles of internal medicine. New York: Mc Graw-Hill;2005.2152-80. 
9. Yusof MI, Al-Astani AD, Jaafar H, Rashid FA. Morphometric analysis of skin microvaculature in the diabetic foot. Singapore Med J. 2008;49:100-4.

10. Lavery LA, Armstrong DG, Wunderlich RP, Mohler MJ, Wendel CS, Lipsky BA. Risk factors for foot infections in individuals with diabetes. Diabetes Care. 2006;29:1288-93.

11. Frier BM, Fisher M. Diabetes Mellitus. In: Boon NA, Colledge NR, Walker BR, Hunter JA. Davidson' principles and practice of medicine. New Delhi: Elsvier;2006:805-47.

12. Boulton AJ, Vileikyte L, Ragnarson-Tennvall G, Apelqvist J. The global burden of DF disease. Lancet 2005;366:1719-24.

13. Gale EAM, Anderson JV. DM and other disorders of metabolism In: Kumar P, Clark M. Kumar and Clark clinical medicine. London: Elsvier;2005:1130-51.

14. Edmonds M. A natural history and frame work for managing DF ulcer: Br J Nurs. Jan 2008;12-25;17(11):S2022.

15. Ertugrul MB, Baktiroglu S, Salman S, Unal S, Akosy M, Berberoglu $\mathrm{K}$, et al. The diagnosis of osteomyelitis of the foot in diabetes: microbiological examination vs. magnetic resonance imaging labeled leukocyte scanning. Diabet Med. 2006;23:649-53.

16. Mark P. Slovenkai MD. Foot problems in diabetes. Medical Clinics of North America Vol. 82, No.4, July 1998;949-71.

17. Gibbons GW, Eliopoulons GM. Infection of the diabetic foot. In Kozak GP, Hoar CS, (Eds.). Management of DF problems. Philadelphia, W B Saunders, 1984:97.

18. M. Lindsay Grayson. DF infections. Antimicrobial therapy. Inf. Dis. Clin. Of North America, Vol 9, No. 1 March 1995;143-61.

19. Grayson ML, Gibbons GW, Habershaw GM, Freeman DV, Pomposeli FB, Rosenblun BI, et al. Use of ampicillin/sulbactem versus Imipenum/Cilastatin in the treatment of limb threatening foot infection in dia- betic cases. Clin. Infect. Dis. 1994;18:683-93.

20. Rao N, Lipsky BA. Optimizing antimicrobial therapy in DF infections. Drugs. 2007; 67:195-214.

21. Alavi SM, Khosravi AD, Sarami A, Dashtebozorg A, Montazeri EA. Bacteriologic study of DF ulcer. Pak J MedSci. 2007;23:681-4.

22. Gadepalli R, Dhawan B, Sreenivas V, Kapil A, Ammini AC, Choudry R. A clinico-microbiological study of DF ulcers in an Indian tertiary care hospital. Diabetic Care. 2006;29:1727-32

23. Jamil M, Amin Z, Choudry TH, Shaheen J, Alvi Z. Management of DF infections. J Coll Physicians Surg Pak. 2001;11:606-10.

24. El-Tahawy AT. Bacteriology of diabetic foot. Saudi Med J. 2000;21:344-7.

25. Lipsky BA, Berendt AR. Principles and practice of antibiotic therapy of DF infections. Diabetes Metab Res Rev. 2000;16(suppl) 1: S42-6.

26. Sharma VK, Khadka PB, Joshi A, Sharma R. Common pathogens isolated in DF infection in Bir Hospital. Kathmandu Univ Med J (KUMJ). 2006;4:295-301.

27. Abdulrazak A, Bitar ZI, Al-Shamali AA, Mobasher LA. Bacteriological study of DF infections. J Diabetes Complications. 2005;19:138-141.

28. Khoharo HK, Ansari S, Qureshi F. DF ulcers. Professional Med J. 2009;16:53-60.

29. Raja NS. Microbiology of DF infection in a teaching hospital in Malaysia: a retrospective study of 194 cases. J Microbiol Immunol Infect. 2007;40:39-44.

30. Hartemann-Heurtier A, Robert J, Jacqueminet S, Ha Van G, Golmard JL, Jarlier V, et al. DF ulcer and multidrug resistant organisms; risk factors and impact. Diabet Med. 2004;21:710-5.

31. Bansal E, Garg A, Bhatia S, Attri AK, Chander J. Spectrum of microbial flora in DF ulcers. Indian J Pathol Microbiol. 2008;51:204-8. 


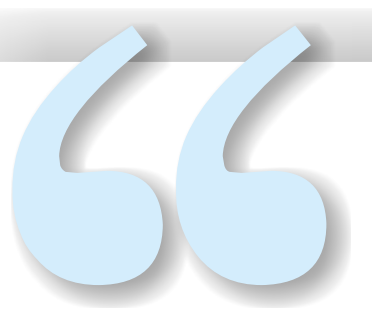

\section{"I survived because the fire inside me burned brighter than the fire around me."}

\section{AUTHORSHIP AND CONTRIBUTION DECLARATION}

\begin{tabular}{|c|c|c|c|}
\hline Sr. \# & Author-s Full Name & Contribution to the paper & Author $=\mathbf{s}$ Signature \\
\hline 1 & Dr. Abdul Ghani Rehimoon & & \\
\hline 2 & Muhammad Tanveer Alam & & ins \\
\hline 3 & Muhammad Saeed Talpur & & \\
\hline 4 & Prof. Muhammad Manssor & & $7 m$ \\
\hline
\end{tabular}

